\title{
Evaluación experimental de un programa virtual de entrenamiento en lectura significativa (e-PELS)
}

\section{Hector Ponce, Mario López, Juan Labra, Jean-Pierre Brugerolles, Cristián Tirado}

VirtuaLab, Universidad de Santiago de Chile, USACH, Santiago

Chile

hponce@usach.cl 


\section{Resumen}

Introducción. El objetivo de esta publicación es presentar los resultados de la evaluación experimental de un programa de entrenamiento para una lectura significativa, constituido por un conjunto de estrategias de aprendizaje incluidas en una aplicación de software denominada e-PELSC (Programa Virtual de Entrenamiento en Lectura Significativa).

Método. La evaluación se llevó a cabo a través de un diseño experimental con grupos de control y expermiental, ambos formados aleatoriamente. Estos grupos estuvieron constituidos por alumnos de 4to año de enseñanza básica que presentaban problemas de comprensión lectora. La hipótesis sometida a procedimiento experimental establecía que los alumnos que participaban (grupo experimental) del programa e-PELS adquirirían un dominio de las estrategias de aprendizaje y mejorarían significativamente su capacidad de comprensión lectora asociada a tal dominio en contraste con los alumnos que no participaron de dicho programa (grupo de control). El procedimiento experimental estuvo constituido por un pretest y postest para medir el nivel de comprensión lectora de los alumnos, tanto del grupo experimental como de control. Para ello, se utilizó la prueba CLP (Complejidad Lingüística Progresiva), estandarizada para Chile. El tratamiento consistió en la participación de los alumnos del grupo experimental en el programa de entrenamiento lector durante 11 sesiones con una duración de 2 horas cada una, dos veces por semana, en el laboratorio de computación del Colegio.

Resultados. Los resultados experimentales confirmaron la hipótesis; los alumnos que participaron en e-PELS lograron el dominio de las estrategias de aprendizaje incluidas en este programa de entrenamiento y mejoraron significativamente su nivel de comprensión lectora comparado con el grupo de control.

Discusión. Los resultados demuestran además que e-PELS constituye una solución concreta, efectiva, replicable, escalable y de bajo costo de implementación que asiste al principal actor del proceso formativo y de aprendizaje - el alumno - en los desafíos que conlleva su particular proceso de construcción de conocimiento.

Palabras Clave: comprensión lectora, estrategias de aprendizaje, habilidades cognitivas, aprendizaje experiencial, organizador gráfico interactivo.

$\begin{array}{ll}\text { Recepción del artículo: } & 05-02-2007 \\ \text { Aceptación provisional: } & 13-05-2007 \\ \text { Aceptación definitiva: } & 18-05-2007\end{array}$




\section{Introducción}

El nuevo marco curricular para la Educación Básica (Decreto 232 del año 2004), definido por el Ministerio de Educación de Chile, señala como uno de sus principios orientadores focalizar el trabajo pedagógico en el aprendizaje más que en la enseñanza, reorientando el trabajo actual, basado principalmente en actividades lectivas e instruccionales a uno fundamentado en actividades de exploración, búsqueda de información y construcción de nuevos conocimientos por parte de los alumnos. Bajo este enfoque, el trabajo pedagógico exige el reconocimiento y consideración tanto de las características individuales de los estudiantes como de sus conocimientos previos; y, por lo tanto, el desarrollo de actividades de aprendizaje diferenciadas y adaptadas a los distintos ritmos y estilos de aprendizaje. Todo ello demanda orientar el aprendizaje hacia el desarrollo de destrezas y habilidades cognitivas, tanto básicas como de orden superior, que doten a los aprendices de herramientas para poner en práctica el aprender a aprender (Novak \& Gowin, 1988), es decir, el aprendizaje estratégico.

El Ministerio de Educación plantea que para avanzar hacia una enseñanza efectiva y poner en práctica estos principios orientadores, "se requiere de recursos curriculares y didácticos que sirvan de referentes y que modelen el cambio esperado" (MINEDUC, 2006). Por lo tanto, se reconoce la relación simbiótica entre recursos curriculares-didácticos y la realización de actividades pedagógicas centradas en el aprendizaje. Esta actividad requiere, a su vez, del diseño de un ambiente de aprendizaje destinado a operacionalizar el enfoque por competencias vigente y a proveer las condiciones para que los estudiantes a partir de sus conocimientos previos, y dadas sus características individuales, construyan nuevos conocimientos. Indudablemente, unos requerimientos adicionales y claves son la presencia de una didáctica respetuosa del perfil multimedial del aprendiz actual, con material de apoyo y una actuación docente estratégica y orientada a motivar el interés y la participación para que dicha construcción sea posible. En especial, el desarrollo de habilidades cognitivas y tal construcción del conocimiento demandan una dotación y apropiación, por parte del aprendiz, de estrategias de aprendizaje para adquirir, codificar, recuperar y apoyar el procesamiento de los contenidos incluidos en dichas actividades de aprendizaje (Amestoy, 2002; Bara, 2001; Román y Gallego, 1994).

Sin embargo, estudios y mediciones tanto nacionales como internacionales señalan las dificultades para hacer efectivos estos nuevos principios orientadores y que redunden en un 
aumento en la calidad de la oferta educativa en Chile. De la variedad de problemas detectados, uno de los de mayor efecto y determinantes para el éxito escolar y profesional es el bajo nivel de comprensión que presentan, tanto niños en edad escolar, como adultos que han pasado por los distintos niveles de formación. Reiteradas mediciones, tales como el IALS, PISA+, SIMCE y PSU, así lo demuestran. Por ejemplo, el estudio internacional PISA+ arroja como resultado que en Chile el 28\% de sus alumnos se encuentra en los niveles más bajos de desempeño lector, en comparación a sólo un 6\% de los países de la OECD (MINEDUC, 2003). En tanto, el estudio IALS de la OECD (2000) indica que apenas un 14\% de la población adulta (entre 15 y 65 años) cuenta sólo con destrezas mínimas en lenguaje para desempeñarse adecuadamente en una sociedad del conocimiento. Según el estudio, la población chilena presenta serias dificultades, por ejemplo, para seguir instrucciones tan simples como identificar correctamente las dosis para niños en un envase de fármaco.

Un mecanismo para dotar al aprendiz-lector de estrategias de aprendizaje adecuadas para desarrollar su comprensión lectora es la implementación de programas de formación para dicho efecto (Román, 2004). En este artículo se presenta la evaluación experimental de un programa de entrenamiento en lectura significativa de textos, que implementa una serie de microestrategias de aprendizaje y cuya práctica es asistida por un módulo desarrollado a partir de componentes de software interactivos. Dicho programa lo hemos denominado e-PELS ${ }^{\odot}$ (Programa Virtual de Entrenamiento en Lectura Significativa).

Tal evaluación de la efectividad del uso sistemático de e-PELS se desarrolló con un grupo de alumnos de 4to año de enseñanza básica en un colegio particular subvencionado (dependencia privada pero con finaciamiento estatal) de la ciudad de Santiago de Chile. Los resultados de la evaluación experimental demuestran que la comprensión lectora de los alumnos que participaron (grupo experimental) del programa de entrenamiento en lectura e-PELS mejoraron significativamente comparado con aquellos alumnos que no participaron de este programa de formación en estrategias de aprendizaje (grupo de control) y que sólo asistieron a sus actividades lectivas normales.

El programa e-PELS fue diseñado considerando las siguientes técnicas o microestrategias de aprendizaje: subrayado de párrafos, coloreado, elaboración de parafraseo, identificación de estructura subyacente, formulación de autopreguntas, organización gráfica de la información, y elaboración de resúmenes. Por lo tanto, no sólo se presenta el efecto de e-PELS 
sobre el nivel de comprensión lectora, sino que también, un análisis detallado de la evolución de cada alumno participante (grupo experimental) respecto al dominio de las estrategias de aprendizaje.

El programa de entrenamiento consistió en 11 sesiones de 2 horas cada una, dos veces por semana, en el laboratorio computacional del Colegio. En cada sesión, los alumnos trabajaron sobre textos fuentes pertinentes a su nivel educacional. Además, se incluyó como parte del programa experimental actividades en papel similares a las desarrolladas en el laboratorio, para que el estudiante trabajara en su casa.

Un aspecto clave observado durante el programa de entrenamiento fue el proceso de construcción de significado evidenciado a partir del texto fuente y de las estrategias de aprendizaje utilizadas para procesar la información contenida en dichos textos.

A continuación, se exponen algunos aspectos conceptuales sobre la comprensión significativa de textos y se explica el Programa Virtual de Entrenamiento en Lectura Significativa e-PELS. El artículo continúa con detalles del método y procedimiento de investigación, los resultados de la evaluación experimental y las principales conclusiones.

\section{Comprensión Significativa de Textos}

El objetivo de evaluar una acción lectora debiera ser el de permitirnos visualizar cómo el lector construye significado en consideración al despliegue de recursos o estrategias de aprendizaje que posee y a partir del texto que se le presenta. En el proceso de lectura de un texto, Condemarín y Medina (2000) señalan que la construcción de significados puede asociarse a tres instancias de la lectura: un antes, durante y después de ella.

Primero, antes de la lectura, se requiere de una serie de herramientas cuyo interés principal es la activación y desarrollo de conocimientos previos que son considerados claves para la comprensión y significación (Ausubel, 1963). Al respecto, son determinantes: la cuantía y calidad de tales conocimientos previos - o su carencia-, y las concepciones erróneas que se pudieran presentar. Se han desarrollado técnicas específicas para activar los conocimientos previos, tales como: (1) la formulación de preguntas previas (anticipadoras) o afirmaciones incompletas; (2) discusiones, comentarios y lluvia de ideas; (3) guías o cuestionarios de anti- 
cipación, entre otros. Todas estas técnicas junto con transparentar la estructura cognitiva previa que posee cada aprendiz lector permiten acercarlo a la temática que se pretende que aprenda (Condemarín y Medina, 2000).

Segundo, interesa observar cómo los aprendices-lectores procesan el significado del texto durante la lectura. Se asume como cierto que un lector experto realiza una serie de acciones, como realizar inferencias o predicciones, hacerse preguntas, corregir errores, entre otros, que le permiten una construcción significativa de nuevos conocimientos. Mediante técnicas tales como: (1) inferencias y predicciones ó (2) preguntas sobre lo leído, se pretende revelar la comprensión de un texto, su carácter literal o inferencial, el nivel de detalles captados, la incorporación de sus experiencias personales y los niveles de creatividad que configuran, en el mejor de los casos, una lectura significativa (Condemarín y Medina, 2000).

Tercero, interesa detectar las necesidades de los alumnos en cuanto al desarrollo de habilidades para sintetizar la información leída, recapitularla, resumirla, comentarla o expresar puntos de vista sobre ella. Conjuntamente, se pretende verificar al alcance de los nuevos saberes al trasferirlos a nuevas situaciones de aprendizaje. Técnicas tales como: (1) el recuerdo o paráfrasis, (2) los organizadores gráficos, (3) los resúmenes, (4) la lectura crítica, (5) el círculo literario, entre otras, pretenden dar cuenta de lo que piensan acerca del texto fuente permitiendo visualizar la reorganización, el procesamiento, la toma de decisiones que de él hagan los aprendices-lectores al considerar o eliminar información y, por qué no, las inferencias que generen (Condemarín y Medina, 2000).

En cada fase se ventila la presencia de procesos universales y particulares que ligados a habilidades cognitivas o del pensamiento se definen como operadores intelectuales que definen cursos de acción adoptados para enfrentar el desafío de construir conocimiento, por ejemplo, de un texto fuente (Amestoy, 2002).

En todas las técnicas -plano potencial- o estrategias de aprendizaje -cuando emerge la intención y decisión de que el aprendizaje ocurra- (Román, 2005) que se mencionan, emergen una serie de actividades que requieren habilidades para la construcción de significado de las lecturas. A su vez, estas requieren ser desarrolladas mediante el uso iterado y sistemático de estrategias de aprendizaje lector. Por lo tanto, la pretensión de evaluar ya no sólo el producto sino que el proceso de construcción de aprendizaje requiere del despliegue de una serie de 
herramientas que en una lógica de acción-observación-reflexión-nueva acción (aprendizaje experencial) permita a los lectores construir aprendizajes efectivos y a los docentes formadores, guías y evaluadores intervenir oportunamente, recoger las evidencias y la evaluation o emisión de juicios- que construyeron los primeros (Condemarín y Medina, 2000).

Luego, las etapas involucradas en tal proceso requieren el ejercicio de habilidades cognitivas como la observación, la comparación, el ordenamiento de hechos y elementos, la clasificación, la síntesis y la representación de información, entre otros, todos ellos definidos como habilidades cognitivas (Monereo, 1991). O como señalan las denominadas "tácticas" de las investigaciones de Schmeck (Schmeck, 1985, en Trufello, 1988) para referirse a las acciones específicas o precisas que lleva a cabo un aprendiz para alcanzar distintos niveles de aprendizaje y que incluyen la categorización, la organización jerárquica de sistemas de ideas, la abstracción, para aprendizajes profundos; o la generación de ejemplos, la traducción a códigos personales, la relación de nuevos contenidos con la experiencia previa, para aprendizajes elaborativos; y la repetición, las mnemotecnias, entre otras, para aprendizajes memorísticos.

Debido a ello, habilidades cognitivas como la memorización, la clasificación, la observación, la síntesis, la argumentación, la inducción, la deducción y la comparación, que debieran estar presentes en todo acto de aprendizaje que pretenda efectividad, son evocadas a la hora de diseñar una solución para la dotación de estrategias que conduzcan a la formación de aprendices también estratégicos (Pezoa \& Labra, 2002).

\section{Programa Virtual de Entrenamiento en Lectura Significativa: e-PELS}

Por lo tanto, a partir de los planteamientos sobre el proceso de lectura significativa, señalados en la sección anterior, y en las habilidades cognitivas presentes en el acto de aprender, y en base a los trabajos de Román (2004) y Román y Gallego (1994), se han adaptado tales principios y bases teóricas para el desarrollo e implementación del programa virtual de entrenamiento en lectura significativa que hemos denominado e-PELS.

Román (2004) propone un programa de entrenamiento en lectura significativa de textos basada en un conjunto de estrategias cognitivas y metacognitivas, conocidas con la sigla ACRA; factibles de manipulación y, por lo tanto, susceptibles de ser enseñadas y gestionadas. 
Los procesos cognitivos básicos identificados dicen relación con (1) estrategias de adquisición de información, (2) estrategias de codificación de información y (3) estrategias de recuperación de información. Además, para el adecuado rendimiento del sistema cognitivo, emergen desde el punto de vista metacognitivo y socioafectivo las (4) estrategias de apoyo al procesamiento de información, que acompañados de un didáctica motivadora tiende a garantizar la significación en su aprendizaje.

Para cada uno de los procesos cognitivos involucrados en estas cuatro estrategias cognitivas y metacognitivas, Román y Gallego (1994) identifican un conjunto amplio de estrategias de estudio a nivel de microestrategias o tácticas de aprendizaje, entre las cuales encontramos: elaboración de resúmenes, construcción de esquemas, estrategias de elaboración, estrategias de memorización, subrayado de párrafos, utilización de signos, intercambio de opiniones, relectura, planificación del tiempo, secuencia de estudio, entre muchos otros.

A partir de dichos desarrollos, el programa de entrenamiento en lectura significativa propuesto por Román (2004) queda compuesto por las siguientes microestrategias de aprendizaje: (1) habilidad para destacar (subrayar y colorear), (2) elaboración de paráfrasis, (3) elaboración de autopreguntas, (4) identificación de estructura subyacente y (5) construcción de mapas conceptuales. No obstante, en el diseño del programa en lectura significativa adoptado en este diseño experimental, e-PELS, se ha ampliado la microestrategia construcción de mapas conceptuales a la de organización gráfica interactiva de la información, se ha fusionado las estrategias 3 y 4 en la denominada estructura de texto y se ha adicionado el resumen como una instancia evaluativa de carácter sumativo y depositario de producciones de texto que se esperan cada vez más significativas; aunque esta estratégia no fue considerada en la evaluación experimental.

Román indica que estas técnicas de estudio y aprendizaje han demostrado reiteradamente su eficacia en distintos contextos en donde se han aplicado. Sin embargo, para que esta efectividad emerja, debe generarse un automatismo cognitivo, es decir, esta secuencia de microestrategias debe ejecutarse iterativamente hasta producirse la sistematización, compilación, encapsulado y empaquetamiento de dichas habilidades en el estudiante.

A continuación, se muestran 2 pantallas propias del programa e-PELS en donde se puede apreciar la implementación de las estrategias de aprendizaje indicadas en el párrafo 
anterior y las funcionalidades del módulo de lectura significativa. Incluye un ejemplo con un texto en el que ya se han utilizado la técnica de destacado que incluye subrayado y coloreado, además del parafraseo (fig. 1). En tanto, en la figura 2, se observa la utilización de un organizador gráfico interactivo denominado "Causa Efecto" para el establecimiento de las relaciones causales que derivan del análisis del texto fuente y en donde cada alumno generará una versión personalizada que incluye su particular representación del fenómeno.

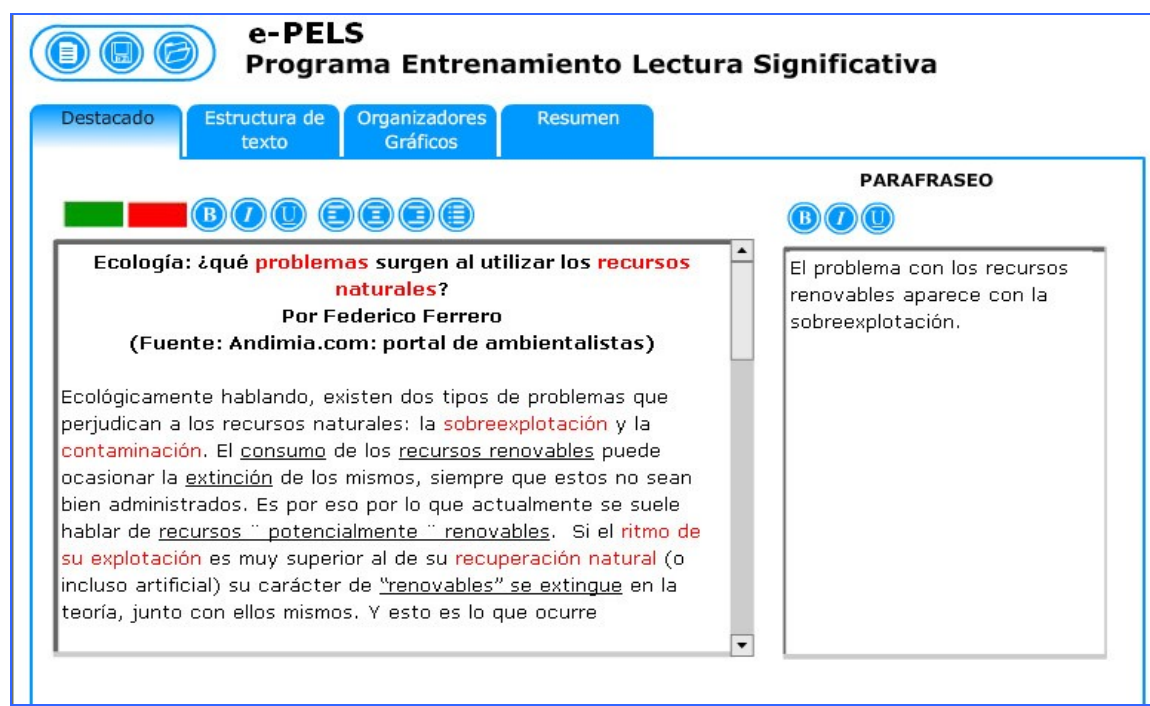

Figura 1: Técnicas de Destacado (incluye coloreado y subrayado) y Parafraseo

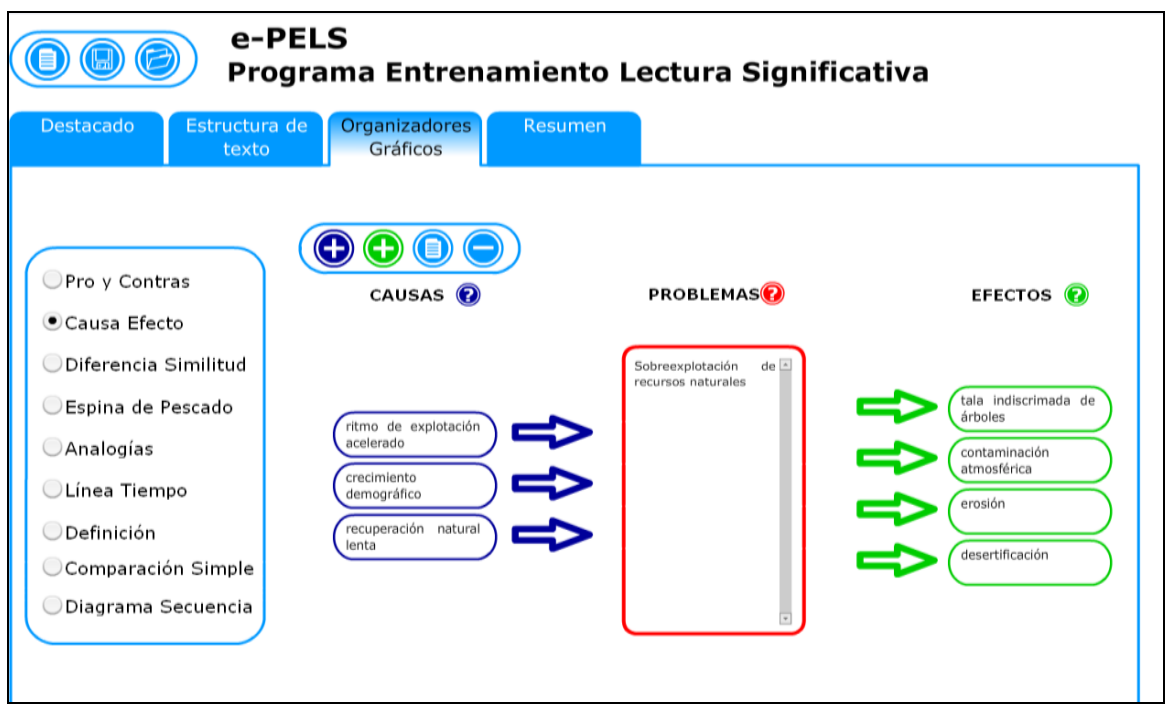

Figura 2: Técnica de Organización Gráfica 


\section{Hipótesis}

Los estudiantes que participan (grupo experimental) del programa de lectura significativa e-PELS adquirirán el dominio de las estrategias de aprendizaje y mejorarán significativamente su capacidad de comprensión lectora, en contraposición a los estudiantes que no participan de dicho programa (grupo de control).

\section{Método}

\section{Participantes}

Los alumnos participantes en esta experiencia corresponden a alumnos que iniciaban su 4to año de enseñanza básica (niños y niñas entre 8 y 9 años de edad) en el Colegio Polivalente Presidente José Manuel Balmaceda, de la ciudad de Santiago. La selección de los alumnos participantes la realizó la psicopedagoga del Colegio, configurándose una lista de 20 niños y niñas que en su totalidad presentaron problemas de comprensión lectora. De 45 alumnos que componían el curso los 20 seleccionados verificaron esta condición luego de habérseles practicado, junto al resto del curso, el Test de Spache (Sepúlveda \& Jofré, 1984). La conformación del grupo experimental y control fue realizada aleatoriamente, conformando 2 grupos de 10 alumnos cada uno.

\section{Variables dependientes}

\section{a) Dominio estrategia de lectura significativa}

Esta variable corresponde al nivel o grado de dominio en la ejecución de las estrategias presentes en e-PELS y exhibidas por los estudiantes-lectores al ser expuestos a la lectura y expectativa de comprensión significativa de un texto. La secuencia de estrategias consideradas corresponde a: destacado, parafraseo, estructura de texto y autopreguntas y organización gráfica de la información. Éstas son consideradas individual y copulativamente tras el fin de desarrollar cada una de las habilidades cognitivas y el procesamiento lector que permita redundar en una mayor comprensión lectora. No obstante, para este estudio, cada una de estas habilidades cognitivas fue tratada como una dimensión de la variable y su medición fue eminentemente cualitativa. 
Para medir el dominio alcanzado por cada estudiante en las estrategias de aprendizaje incluidas en e-PELS, se utilizó una rúbrica de evaluación cualitativa basada en listas de cotejos. En la sección 5 de este artículo se presentan, junto a los resultados experimentales, los indicadores utilizados para construir dichas rúbricas.

\section{b) Comprensión Lectora}

La comprensión lectora, como variable dependiente, se definió de acuerdo a lo establecido por la Prueba de Comprensión Lectora de Complejidad Lingüística Progresiva (CLP) (Alliende, Condemarín y Milicic, 2004), la cual se encuentra estandarizada para Chile. En ella, el fenómeno de la comprensión es entendido, por una parte, considerando y aceptando las dos concepciones extremas existentes y, por otra, en un nivel más operativo, de acuerdo al nivel de complejidad de los textos y de las características específicas de los grupos de lectores para quienes van dirigidos dichos textos. La primera visión adopta una posición intermedia entre la idea de comprensión lectora como la captación del sentido manifiesto, explícito o literal de un texto determinado y la idea opuesta de comprensión lectora como la vinculación con la particular visión del mundo que cada lector posee en función de su experiencia y de los aportes que formule.

Sin embargo, más allá de la discusión que pueda emerger, es el enfoque operativo el que resuelve tal encrucijada considerando las características psicográficas comunes de grupos de lectores (edad, nivel de escolaridad y de aprendizaje lector, entre otros). Para ello, CLP, como instrumento de medición, define ocho niveles, lo que implica esfuerzos incrementales para su correcta comprensión. En esta experiencia, se definió como pretest, la prueba CLP nivel 3 forma A, y como postest, la prueba CLP nivel 3 forma B.

Si bien la complejidad para estos instrumentos utilizados estaría en función tanto de la extensión de los textos presentados al alumno como del nivel de concreción o de abstracción de los sujetos a los que referencian, el nivel 3 utilizado en la experimentación incluye textos narrativos breves con elementos concretos y acciones perfectamente individualizadas. Los textos extensos, de naturaleza más compleja y que incluyen abstracciones con sujetos colectivos y hechos de carácter general son contemplados en los últimos niveles lectores ( 7 y 8 especialmente). 


\section{Variable Independiente}

\section{a) Programa de Entrenamiento en Lectura Significativa}

El programa de entrenamiento consiste en una secuencia estructurada y programada de actividades instruccionales cuyo fin es la dotación, apropiación, desarrollo y transferencia de estrategias de aprendizaje lector, que cristalizada en el software e-PELS, facilita en los estudiantes apoderarse de las habilidades cognitivas requeridas para leer en forma comprensiva un texto dado. Para esta variable distinguiremos dos valores posibles: (1) con programa de entrenamiento y (2) sin programa de entrenamiento, correspondientes al grupo experimental y de control respectivamente.

Considerando que e-PELS fue concebido para el entrenamiento en estrategias de aprendizaje que impacten directamente sobre la comprensión lectora, se diseñaron y realizaron sesiones en el laboratorio de computación del colegio para presentar a los estudiantes una selección de textos cortos contemplados en los planes y programas de estudio de su nivel. Luego, con la asistencia del docente a cargo de las sesiones, se procedió a entrenar en la lógica de cada estrategia lectora, para más tarde ponerla en práctica en el computador utilizado por cada estudiante.

El entrenamiento se inicia al aplicar una estrategia lectora sobre un primer texto fuente seleccionado y siguiendo las instrucciones del docente, expuestas con la ayuda de un proyector. La idea central de esta parte del entrenamiento es presentar la estategia, compartir su finalidad como ayuda para la comprensión lectora y operar con toda la funcionalidad provista por el software e-PELS, permitiendo, a su vez, practicar y aclarar dudas en torno a su modo de operación.

Seguido, se presenta una segunda lectura que debió ser analizada por el estudiante sin la intervención o ayuda del encargado. En esta etapa se le pidió al aprendiz utilizar la estrategia programada en la sesión, procesar con ella esta segunda lectura y, más tarde, compartir su experiencia con la clase. Esta última retroalimentación se lleva a cabo nuevamente con la ayuda del proyector, permitiendo que cada participante comente y evalúe su forma de operar y la del resto de sus compañeros. El objetivo es visualizar y concluir con las mejores prácticas, determinando y corrigiendo las desviaciones en cuanto al objetivo de la estrategia que se está aprendiendo. Y para asegurar la apropiación, se hacía entrega de material impreso contenien- 
do una actividad a efectuar en casa para la práctica de la estrategia estudiada en cada sesión. Tal impreso es visualmente idéntico a los diseños en la aplicación de software que implementa e-PELS.

Finalmente, sesión tras sesión se fue revisando en forma sumativa la apropiación de las estrategias vistas en la sesiones anteriores. Se pedía que luego de atender a la estrategia que se presentaba en cada sesión, se incorporara al análisis de nuevos textos todas las estrategias provistas anteriormente. Junto con ello, las tareas fueron gradualemente aumentando en complejidad al requerir al aprendiz-lector un procesamiento de la lectura con cada vez más estrategias.

\section{Procedimiento}

El procedimiento experimental consistió principalmente en tres fases: (1) evaluación pretest, (2) aplicación e-PELS al grupo experimental, y (3) evaluación postest. La primera fase incluyó la evaluación de la comprensión lectora a través de la "Prueba CLP nivel 3 Forma A" a ambos grupos (control y experimental). En ella, se constató que ambos grupos presentaban problemas de comprensión lectora y además que resultaban equivalentes en relación a esta variable (ver sección 5.1).

La segunda fase, consistió en la aplicación del tratamiento al grupo experimental, correspondiente a la participación de los estudiantes de este grupo en el Programa Virtual de Entrenamiento en Lectura Significativa, e-PELS. Este programa incluyó 11 sesiones de entrenamiento (martes y jueves) de 2 horas cada una en el laboratorio de computación del Colegio y una serie de actividades en formato impreso de similar naturaleza y complejidad para que el estudiante desarrollara en su casa. Con esto último, se privilegió el uso iterado pro sistematización. La psicopedagoga estuvo a cargo de enseñar a los estudiantes cada una de las estrategias incluidas en e-PELS, con la asistencia, una vez por semana, de uno de los investigadores. En algunas ocasiones fue necesaria la intervención del encargado del laboratorio computacional para resolver problemas de orden técnico.

Cada una de las sesiones fue programada evocando el denominado aprendizaje experiencial (Kolb, 1984). Es decir, la experiencia acumulada en una sesión es transferida a la sesión siguiente, constituyéndose en forma continua en un andamiaje estructurado y sistemático para alcanzar el dominio de las estrategias y la significación de los aprendizajes lectores. 
Para culminar, una vez finalizado el programa de entrenamiento, a los alumnos tanto del grupo experimental como del grupo de control se les solicitó que respondieran la "Prueba CLP nivel 3 Forma B" a fin de dimensionar los avances en las variables experimentales dependientes.

\section{Resultados}

A continuación se presentan: (1) los resultados respecto al nivel de comprensión lectora alcanzado por los estudiantes, tanto del grupo experimental como de control, medido en dos instantes: antes del inicio del entrenamiento con la "Prueba CLP Forma A" y después del programa de entrenamiento con la "Prueba CLP Forma B"; y (2) la evolución en el nivel de dominio de cada una de las estrategias de aprendizaje presentes en e-PELS.

\section{Nivel de Comprensión Lectora}

\section{Resultados Pretest-Postest}

En las tablas 1 y 2 se presentan los resultados alcanzados por los grupos experimentales y de control tanto al inicio del programa como una vez finalizado el programa de entrenamiento en el que participaron los primeros. Se presentan los resultados del pretest y postest con sus respectivos diferenciales.

Los resultados del pretest (Prueba CLP Nivel 3 forma A) constituyen un diagnóstico sobre el nivel de comprensión lectora y el perfil de ingreso al programa de entrenamiento. En tanto, los resultados del postest (Prueba CLP Nivel 3 Forma B), muestran el nivel de comprensión lectora con posterioridad a la participación de los alumnos del grupo experimental en el Programa de Entrenamiento e-PELS.

\section{Pretest}

Se observa en la tabla 1 que los alumnos del grupo experimental muestran deficiencias en su nivel de comprensión lectora comparado con el grupo de referencia CLP (ver puntuaciones en Bruto, Z, y Percentil). 
Respecto al grupo de control, los resultados obtenidos después de la aplicación de la "Prueba CLP Forma A" son similares a los del grupo experimental. De hecho, no existe diferencia significativa entre ambos grupos $(\mathrm{t}$-student $=0.730, \mathrm{p}$-valor $=0.474, \mathrm{df}=18$ y $\alpha=.05)$.

Tabla 1: Pretest - Postest Grupo Experimental

\begin{tabular}{|c|c|c|c|c|c|c|c|c|c|}
\hline \multirow{4}{*}{$\begin{array}{l}\text { Grupo Expe- } \\
\text { rimental }\end{array}$} & \multicolumn{9}{|c|}{ PUNTAJES CLP } \\
\hline & \multicolumn{3}{|c|}{ BRUTO } & \multicolumn{3}{|c|}{$\mathrm{Z}$} & \multicolumn{3}{|c|}{ Percentil } \\
\hline & Pre & Post & Difer. & Pre & Post & Difer. & Pre & Post & Difer. \\
\hline & A & B & $\Delta$ & A & B & $\Delta$ & A & B & $\Delta$ \\
\hline Alumno 1 & 12 & 12 & 0 & $-0,89$ & $-0,91$ & $-0,02$ & 20 & 20 & 0 \\
\hline Alumno 2 & 9 & 12 & 3 & $-1,65$ & $-0,91$ & 0,74 & 10 & 20 & 10 \\
\hline Alumno 3 & 12 & 15 & 3 & $-0,89$ & $-0,06$ & 0,83 & 20 & 40 & 20 \\
\hline Alumno 4 & 14 & 19 & 5 & $-0,37$ & 1,07 & 1,44 & 30 & 90 & 60 \\
\hline Alumno 5 & 14 & 9 & -5 & $-0,37$ & $-1,76$ & $-1,39$ & 30 & 10 & -20 \\
\hline Alumno 6 & 12 & 17 & 5 & $-0,89$ & 0,51 & 1,40 & 20 & 70 & 50 \\
\hline Alumno 7 & 7 & 12 & 5 & $-2,17$ & $-0,91$ & 1,26 & 10 & 20 & 10 \\
\hline Alumno 8 & 15 & 8 & -7 & $-0,12$ & $-2,04$ & $-1,92$ & 40 & 10 & -30 \\
\hline Alumno 9 & 17 & 13 & -4 & 0,39 & $-0,63$ & $-1,02$ & 60 & 30 & -30 \\
\hline Alumno 10 & 14 & - & - & $-0,37$ & - & - & 30 & - & - \\
\hline
\end{tabular}

Los resultados de la aplicación de la prueba CLP, tanto al grupo experimental como al grupo de control evidencian que los alumnos se encuentran significativamente bajo el promedio comparado con el grupo de estandarización CLP (nivel 3). Para el grupo experimental, sólo un estudiante se encuentra sobre el promedio (alumno $9, \mathrm{Z}=0.39$ ) y para el grupo de control, dos estudiantes se encuentran en el promedio respecto al grupo de estandarización (alumnos 3 y 9). El resto de los alumnos muestra rendimientos muy inferiores en relación al grupo de referencia CLP.

En definitiva, los datos del Pretest nos permiten establecer que ambos grupos son homogéneos respecto al nivel de comprensión lectora antes de iniciar el programa de entrenamiento. De esta forma, la formación aleatoria de los grupos y los resultados obtenidos en el pretest garantizan el diseño experimental de esta investigación. 
Tabla 2: Pretest - Postest Grupo Control

\begin{tabular}{|c|c|c|c|c|c|c|c|c|c|}
\hline \multirow{4}{*}{$\begin{array}{l}\text { Grupo } \\
\text { Control }\end{array}$} & \multicolumn{9}{|c|}{ PUNTAJES CLP } \\
\hline & \multicolumn{3}{|c|}{ BRUTO } & \multicolumn{3}{|c|}{$\mathrm{Z}$} & \multicolumn{3}{|c|}{ Percentil } \\
\hline & Pre & Post & Difer. & Pre & Post & Difer. & Pre & Post & Difer. \\
\hline & A & B & $\Delta$ & A & B & $\Delta$ & A & B & $\Delta$ \\
\hline Alumno 1 & 14 & - & - & -0.37 & - & - & 30 & - & - \\
\hline Alumno 2 & 15 & 15 & 0 & -0.12 & -0.06 & 0,06 & 40 & 40 & 0 \\
\hline Alumno 3 & 16 & 14 & -2 & 0.14 & -0.34 & $-0,48$ & 50 & 40 & -10 \\
\hline Alumno 4 & 13 & 13 & 0 & -0.63 & -0.63 & 0,00 & 30 & 30 & 0 \\
\hline Alumno 5 & 7 & 11 & 4 & -2.17 & -1.19 & 0,98 & 10 & 20 & 10 \\
\hline Alumno 6 & 14 & 15 & 1 & -0.37 & -0.06 & 0,31 & 30 & 40 & 10 \\
\hline Alumno 7 & 14 & 14 & 0 & -0.37 & -0.34 & 0,03 & 30 & 40 & 10 \\
\hline Alumno 8 & 12 & 13 & 1 & -0.89 & -0.63 & 0,26 & 20 & 30 & 10 \\
\hline Alumno 9 & 16 & 15 & -1 & 0.14 & -0.06 & $-0,20$ & 50 & 40 & -10 \\
\hline Alumno 10 & 14 & 12 & -2 & -0.37 & -0.91 & $-0,54$ & 30 & 20 & -10 \\
\hline
\end{tabular}

\section{Postest}

En la tabla 1, se observa que cinco de los nueve alumnos del grupo experimental que rindieron la "Prueba CLP Forma B" (Postest) y que participaron activamente del programa ePELS mejoraron significativamente su nivel de comprensión lectora en relación al Pretest ( $\mathrm{t}$ student $=4.34, \mathrm{p}$-valor $=0.007, \mathrm{df}=5$ y $\alpha=.05$ ). Sin embargo, tres de los nueve alumnos muestran un deterioro significativo en su desempeño lector comparado con el pretest. Uno de ellos no muestra variación y otro no rindió la prueba CLP Forma B (este último alumno participó sólo esporádicamente en e-PELS).

Ahora, las puntuaciones $\mathrm{Z}$ indican que cinco alumnos logran un mejor nivel de comprensión lectora, aunque el resultado sigue situando a 3 alumnos bajo el promedio en relación al grupo de estandarización CLP, en tanto, 2 alumnos logran superar dicho promedio, alcanzando niveles óptimos para el nivel en que se encuentran (alcanzando percentil 90 y 70).

En la tabla 2, se observa que el grupo de control no evidencia cambios significativos en su nivel de comprensión lectora medido con la prueba CLP después de haber transcurrido 4 meses entre el pretest y postest. Se observa que el desempeño en el postest (CLP forma B) comparado con el pretest (CLP forma A) no presenta diferencias significativas ( $t$ student $=0.107, \mathrm{p}$-valor $=0.915, \mathrm{df}=16 \mathrm{y} \alpha=.05)$. Incluso, analizando los datos por subgrupos, es decir, a aquellos que evidencian algún grado de mejoras en puntaje bruto, dichas diferencias no son significativas. 
Es más, alumnos que se encontraban sobre el promedio ( $Z$ positivo) presentan ahora un deterioro, aunque marginal ( $\mathrm{Z}$ negativo). Al igual que para el grupo experimental, 3 alumnos disminuyen significativamente su desempeño lector, y sólo un alumno logra incrementar en 4 puntos su puntaje en el pretest, pero no logra superar el promedio para el grupo de estandarización CLP.

No obstante lo anterior, es importante recordar que tanto el grupo experimental como el grupo de control, están conformados por alumnos diagnosticados con dificultades de comprensión lectora, $\mathrm{y}$ tanto el pretest y postest tienden a corroborar dichos antecedentes. Por ende, para los análisis y conclusiones se ha considerando tal panorama.

Por lo tanto, dado los resultados observados tanto para el grupo experimental como para el grupo de control, resulta alentador observar que la mayoría de los estudiantes que han participado en el programa de entrenamiento en lectura significativa e-PELS muestran un mejor desempeño en su nivel de comprensión lectora. Asumiendo que otras variables no se vieron alteradas, que el período lectivo siguió su curso normal tanto para el grupo de experimentación como para el grupo de control, es posible atribuir dicho mejoramiento a la participación de los alumnos en el programa de entrenamiento e-PELS, confirmando de esta forma la hipótesis experimental.

Por otra parte, al prestar atención al desempeño del grupo de control, es notorio que no exista una variación significativa en el nivel de comprensión lectora como resultado de su condición de alumnos de cuarto año básico que asisten regularmente a clases. En otras palabras, lo esperable, en condiciones normales, es que la instrucción tradicional genere un efecto incremental positivo sobre la capacidad de comprensión lectora para ambos grupos (control y experimental), por el sólo hecho de asistir a dicha instrucción o actividad lectiva y considerando que entre el pretest y el postest habían transcurrido 4 meses lectivos.

Sin embargo, dicha variación incremental positiva sólo se evidencia en los resultados del grupo experimental que participa de e-PELS, confirmando nuestra hipótesis experimental. La evidencia indica que los resultados se deben principalmente a la participación de los alumnos en el programa e-PELS, que implica principalmente, el entrenamiento en un conjunto de estrategias de aprendizaje para la dotación, desarrollo y transferencia de competencias lecto- 
ras. A continuación se presentan los resultados en el dominio de las estrategias de aprendizaje incluidos en e-PELS.

\section{Dominio Estrategias de Aprendizaje}

En esta sección se presentan la evolución de cada estudiante en relación al dominio alcanzando en cada una de las estrategias de aprendizaje que ejercitaron en cada una de las sesiones incluidas en el programa e-PELS.

\section{Destacado}

Para el análisis de la estrategia de destacado se utilizaron los siguientes indicadores que constituyen una rúbrica de evaluación cualitativa basada en una lista de cotejos.

Tabla 3: Indicadores Evaluación Destacado

\begin{tabular}{|c||c|}
\hline \multicolumn{1}{|c||}{ Indicador } & \multicolumn{1}{c|}{ El alumno: } \\
\hline $\begin{array}{c}\mathbf{1} \\
\text { Reconocimiento }\end{array}$ & $\begin{array}{l}\text { Identifica y selecciona por extensión los elementos explícitos presentes en } \\
\text { el texto, por ejemplo, personaje, problemas, situaciones, título, entre } \\
\text { otros. }\end{array}$ \\
\hline $\begin{array}{c}\mathbf{2} \\
\text { Selección }\end{array}$ & $\begin{array}{l}\text { Destaca las palabras o ideas importantes que constituyen pistas para re- } \\
\text { sumir de qué trata o cuál es la temática del texto. }\end{array}$ \\
\hline $\begin{array}{c}\mathbf{3} \\
\text { Discriminación }\end{array}$ & $\begin{array}{l}\text { Diferencian mediante el uso de distintas tipologías del destacado las ideas } \\
\text { principales de las secundarias; por ejemplo, uso de coloreado rojo y ver- } \\
\text { de. }\end{array}$ \\
\hline
\end{tabular}

Como se observa en el siguiente gráfico, en las primeras sesiones, la mayoría de alumnos no demuestra dominio por la estrategia de destacado; ni siquiera eran capaces de diferenciar los elementos explícitos mínimos que se constituyen en pistas o claves para un posterior entendimiento del mensaje incluido en el texto respectivo. Esto se observa en el gráfico 1 en que todos los alumnos comenzaron en un nivel en que pese a reconocer la técnica, evidencian uso inadecuado, para ambos ambientes — software y papel. 


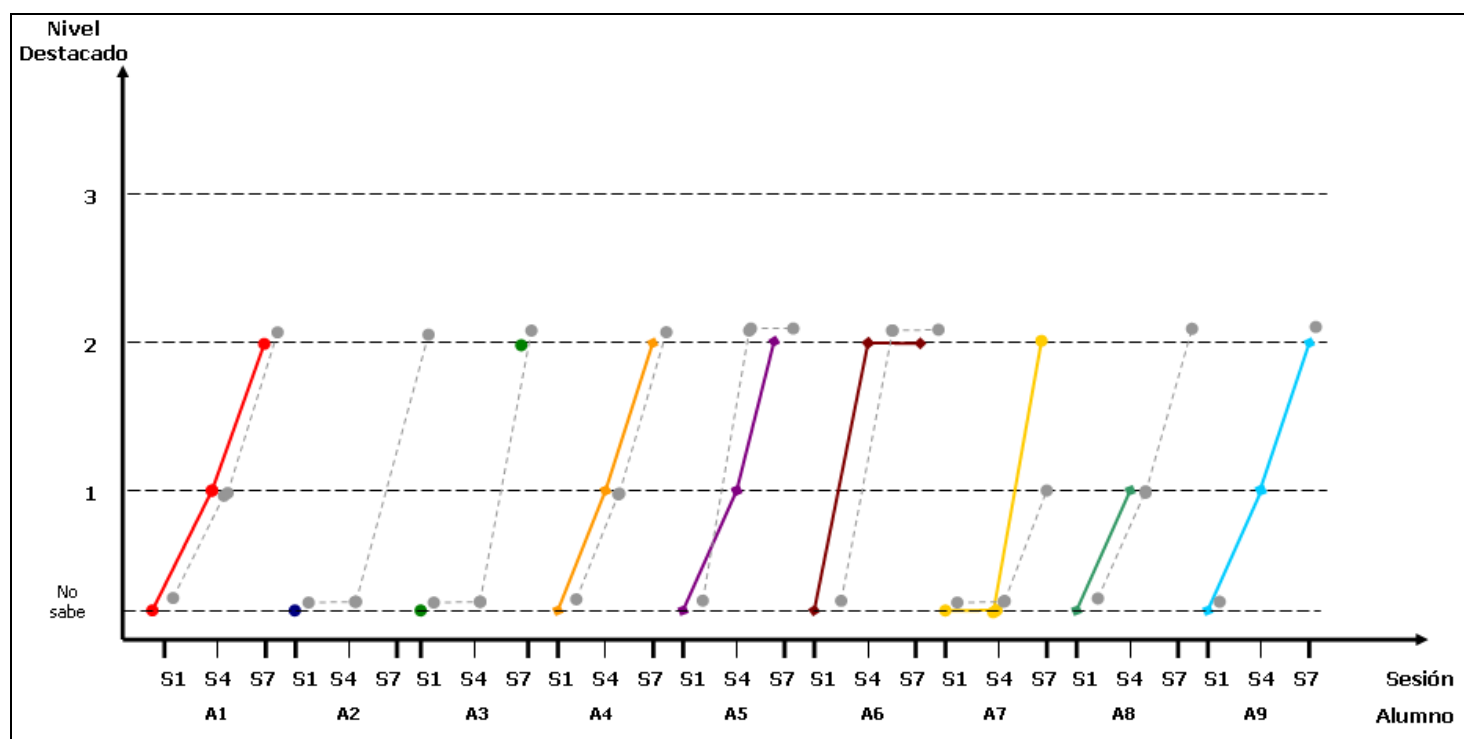

\section{Gráfico 1: Evolución Estrategia Destacado}

Nota: Linea continúa color actividad en e-PELS, linea discontinua indica desarrollos en papel (tareas).

Después de 7 sesiones de entrenamiento, se evidencia una evolución positiva en el uso de la estrategia de destacado. La mayoría identifica las claves de cada párrafo sin recurrir en detalles innecesarios o, más bien, destacados en extenso. Concluyen en un nivel de selección o análisis en donde atendiendo a esos elementos referenciados se puede tener una idea más o menos clara de lo que quiere comunicarse en cada párrafo que compone el texto.

A continuación se presentan un ejemplo (figura 3) de destacado típico durante las primeras sesiones. Todo parece tener relevancia por no saber discriminar aún entre las ideas claves y las accesorias o secundarias, no evidenciándose una selección indagatoria conciente.

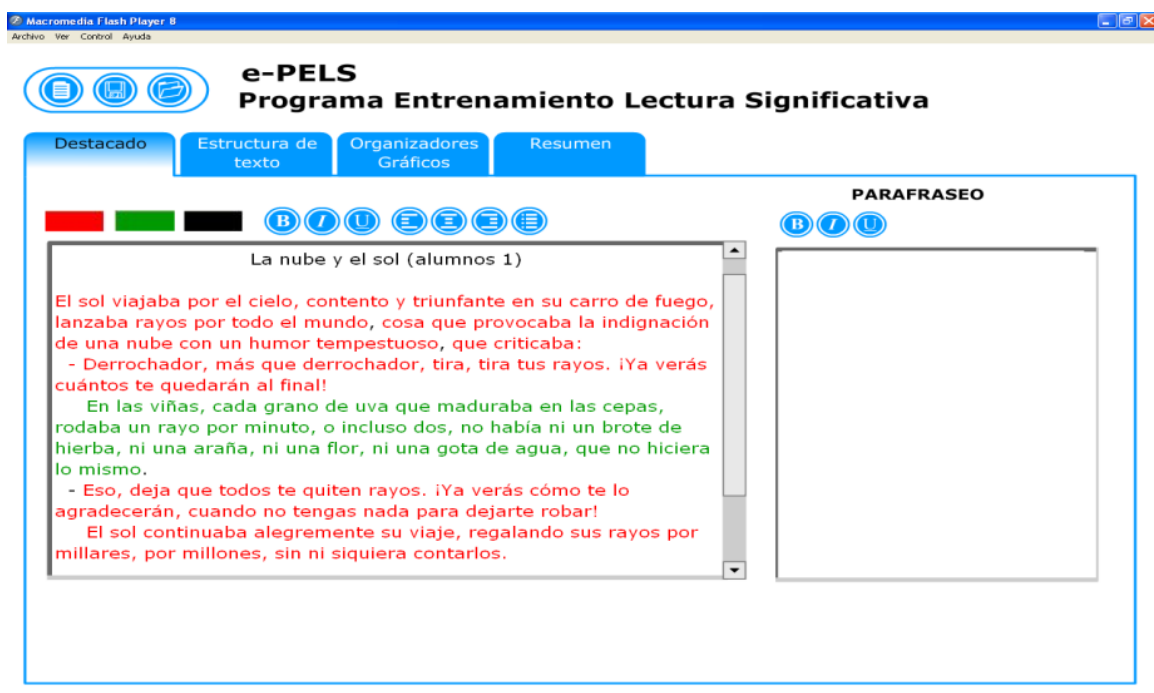

Figura 3: Destacado No Selectivo 
En la siguiente figura, que muestra la utilización de la estrategia de destacado durante la sesión 7, donde la vinculación con las otras estrategias provistas en e-PELS era recurrente, se observa un destacado del tipo selectivo indagatorio.

Se observa en la figura 4 que el destacado comienza a concentrarse en las ideas importantes que presenta el texto y que ya representan con más fidelidad las ideas del autor de la fuente. La lectura de las palabras destacadas podría prescindir de ilaciones y ya se tiene un sentido al menos global de mensaje. Además, una mejor calidad del destacado resulta clave en el procesamiento posterior del texto fuente a través de la estrategia de parafraseo.

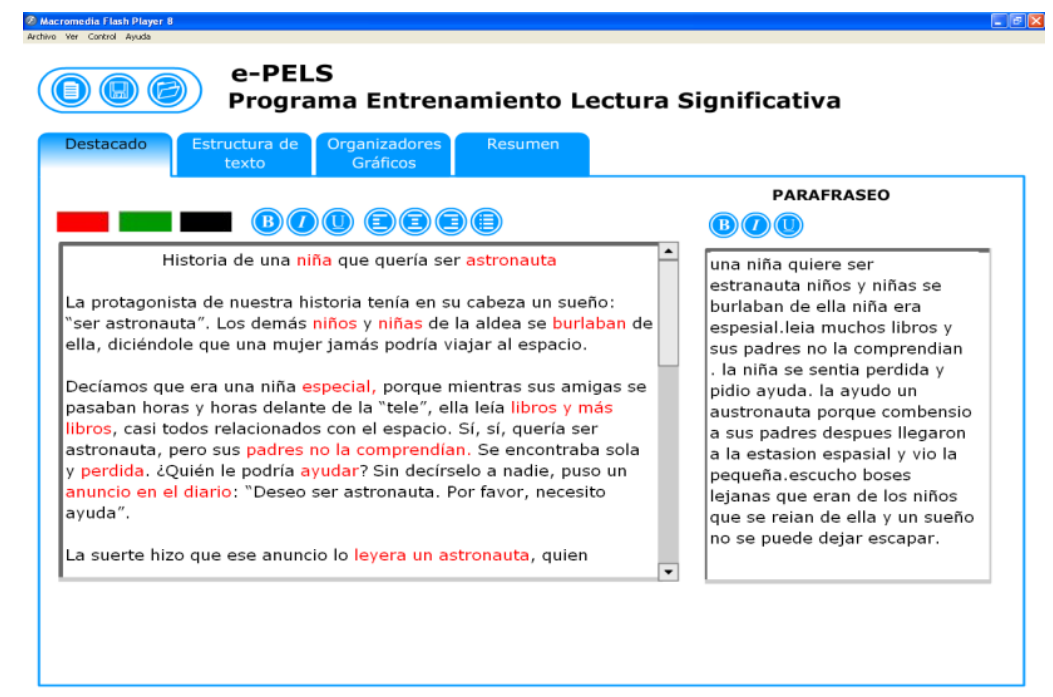

Figura 4: Destacado Selectivo Indagatorio

\section{Parafraseo}

Para el análisis de la estrategia de parafraseo se utilizaron los siguientes indicadores que constituyen una evaluación del tipo cualitativa basada en una lista de cotejo. 
Tabla 4: Indicadores Evaluación Parafraseo Indicadores Evaluación Parafraseo (Adapt. de Condemarín y Medina, 2000)

\begin{tabular}{|c|l|}
\hline Nivel & \multicolumn{1}{c|}{ El alumno: } \\
\hline $\begin{array}{c}\mathbf{1} \\
\text { Incoherencia }\end{array}$ & $\begin{array}{l}\text { No da cuenta de los detalles; agrega elementos no pertinentes, es poco co- } \\
\text { herente, incompleto e incomprensible. }\end{array}$ \\
\hline $\begin{array}{c}\mathbf{2} \\
\text { Reconocimiento par- } \\
\text { cial }\end{array}$ & $\begin{array}{l}\text { Da cuenta de algunas ideas importantes y algunas secundarias, incluye in- } \\
\text { formaciones no pertinentes, tiene un cierto nivel de coherencia es relativa- } \\
\text { mente completo y bastante comprensible. }\end{array}$ \\
\hline $\mathbf{3}$ & $\begin{array}{l}\text { Da cuenta de las ideas principales, incluye ideas secundarias pertinentes, es } \\
\text { coherente, completo y comprensible. }\end{array}$ \\
\hline $\mathbf{4}$ & $\begin{array}{l}\text { Incluye enunciados que resumen el texto; incluye todas las ideas importantes } \\
\text { y las secundarias pertinentes, es coherente completo y comprensible }\end{array}$ \\
\hline $\begin{array}{c}\text { Síntesis } \\
\text { Abstracción }\end{array}$ & $\begin{array}{l}\text { El alumno hace generalizaciones que van más allá del texto; incluye enun- } \\
\text { ciados que resumen el texto; todas las ideas importantes y las ideas secunda- } \\
\text { rias son pertinentes; es coherente, completo y comprensible }\end{array}$ \\
\hline
\end{tabular}

La capacidad de articular frases personales más significativas se va incrementando conforme las sesiones exigen la utilización de la técnica, tal como lo ilustra el gráfico 2. El aspecto funcional que al principio consagra a la estrategia de parafraseo como una técnica y un fin, de a poco se va transformando en un medio para producir pequeños trozos de texto (parafraseos) cada vez más personalizados y significativos.

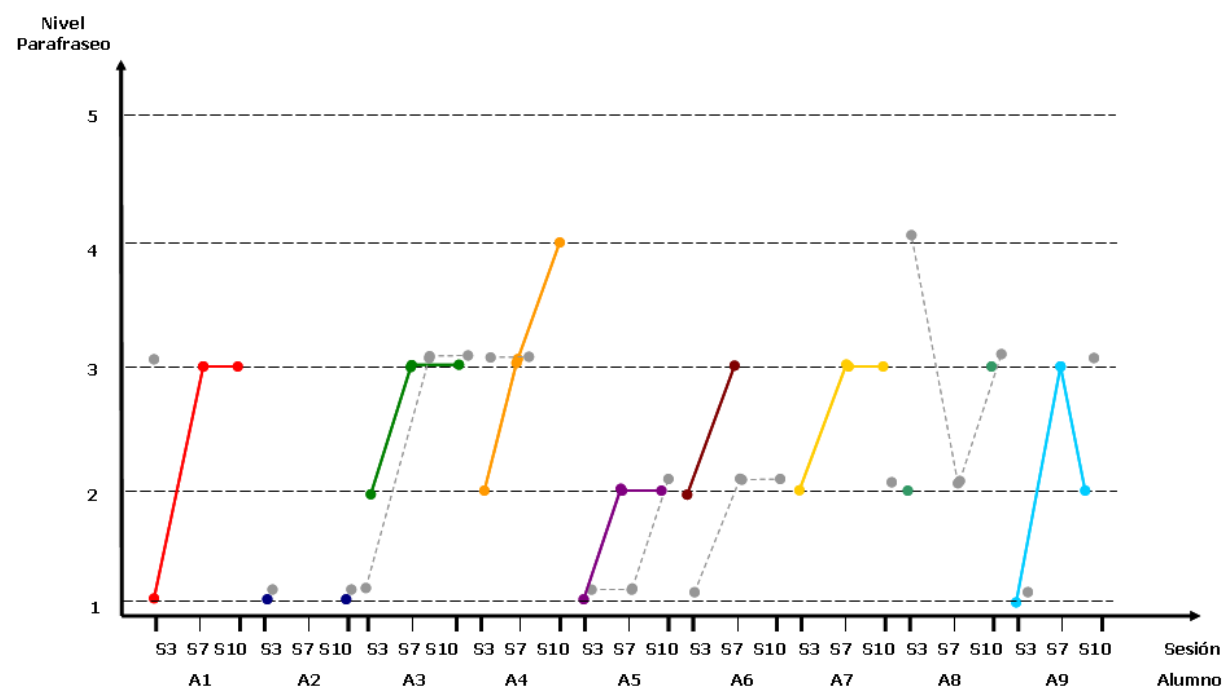

Gráfico 2: Evolución Estrategia Parafraseo

Nota: Linea continúa color actividad en e-PELS, linea discontinua indica desarrollos en papel (tareas). 
La síntesis como habilidad del pensamiento o destreza de orden superior (niveles 4 y 5) está aún vedada para los jóvenes en este nivel (básico o primario). Está comprobado que se consigue en niveles superiores de formación y en el ejercicio continuo de componer apreciaciones de carácter global (Amestoy, 2002). Sin embargo, tal capacidad es sustituida por los jóvenes por la construcción de frases en donde son capaces de articular correctamente los elementos explícitos del texto fuente. Esto lo consiguen al producir "nuevas frases" con "enlaces o ilaciones personales" para tales elementos. Son sus propias palabras las que actúan como elementos vinculantes; aquellas que contienen sus códigos lingüísticos más habituales y que le otorgan sentido al mensaje del que eran antes receptores pasivos.

En la siguiente figura se observa la producción del parafraseo que constituye más bien una reproducción casi literal del texto fuente, y que muestra altos grados de incoherencia en su construcción.

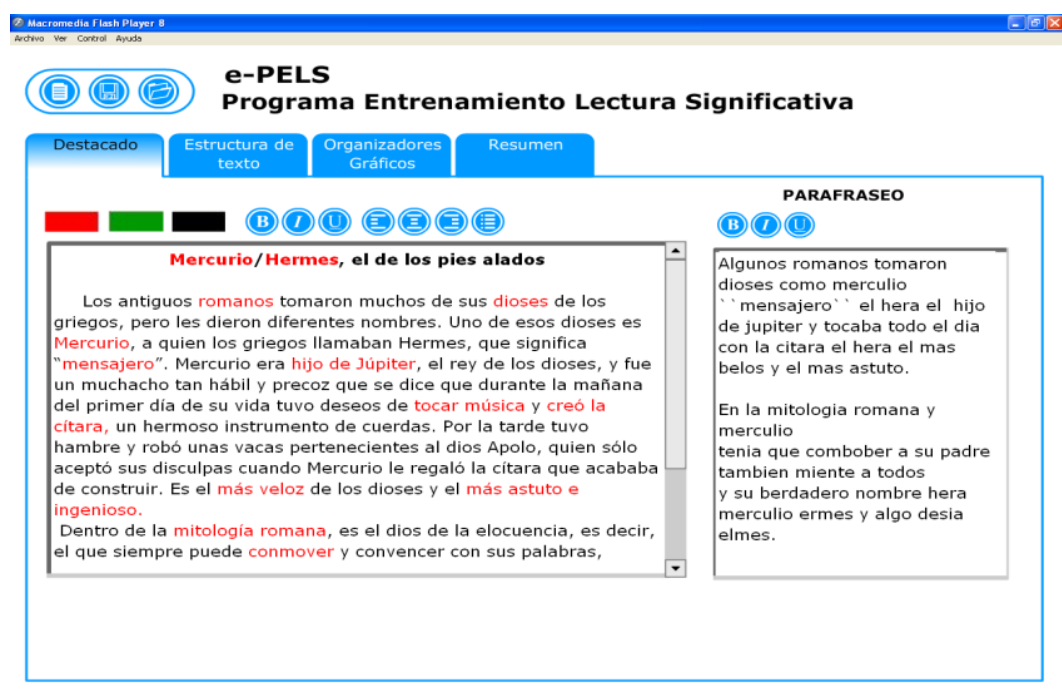

Figura 5: Parafraseo de Escasa Coherencia

La figura 6 muestra un parafraseo que se construye a partir del destacado y que logra una síntesis coherente y altamente comprensible, aunque persiste la tendencia a reproducir el tenor literal del texto fuente. 


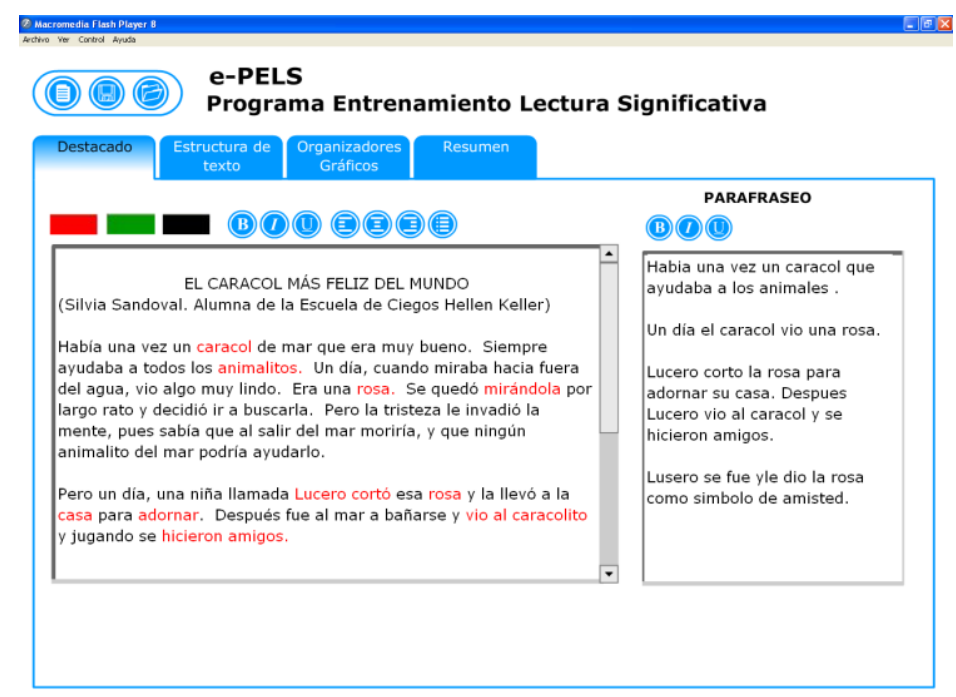

Figura 6: parafraseo sintético

Las técnicas de destacado y parafraseo descritas comienzan a exhibir una madurez en el uso por parte de los alumnos. Esta madurez se traduce no sólo en la apropiación de las estrategias de aprendizaje, sino que también, en un mejoramiento en la lectura selectiva una primera aproximación hacia la producción significativa de textos, que evidencia grados crecientes de comprensión de los textos fuentes utilizados.

\section{Estructura de Texto y Autopreguntas}

Para el análisis de la estrategia que se relaciona con la estructura de texto subyacente y autopreguntas se utilizaron los siguientes indicadores que constituyen una rúbrica de evaluación cualitativa basada en una lista de cotejos.

Tabla 5: Indicadores Evaluación Estructura de Texto y Autopregunta

\begin{tabular}{|c|l|}
\hline Indicador & \multicolumn{1}{c|}{ El alumno: } \\
\hline $\begin{array}{c}\mathbf{1} \\
\text { Reconocimiento }\end{array}$ & $\begin{array}{l}\text { Identifica la estructura o "esqueleto" que caracteriza al tipo de texto que se } \\
\text { está leyendo. }\end{array}$ \\
\hline $\mathbf{2}$ & $\begin{array}{l}\text { Relaciona de forma correcta los elementos explícitos del texto con cada } \\
\text { componente de la estructura subyacente. Produce un vaciado de cada ele- } \\
\text { mento en su casillero correspondiente, demostrando la aprehensión del con- } \\
\text { tenido. }\end{array}$ \\
\hline $\mathbf{3}$ & $\begin{array}{l}\text { Contesta en forma clara y pertinente las autopreguntas que cada componente } \\
\text { de la estructura de texto le hace. En el mejor de los casos, logra establecer } \\
\text { una relación coherente entre el texto y su experiencia. }\end{array}$ \\
\hline
\end{tabular}


El gráfico 3 exhibe como evoluciona el dominio de la estrategia de estructura de texto y autopreguntas, desde un nivel de reconocimiento (nivel 1) hasta un nivel de integración y coherencia. Se observa que la mayoría de los alumnos que sólo alcanzaban a reconocer la estructura subyacente, están ahora en condiciones de relacionar e integrar convenientemente los elementos explícitos presentes en el texto que se les presenta (nivel 2).

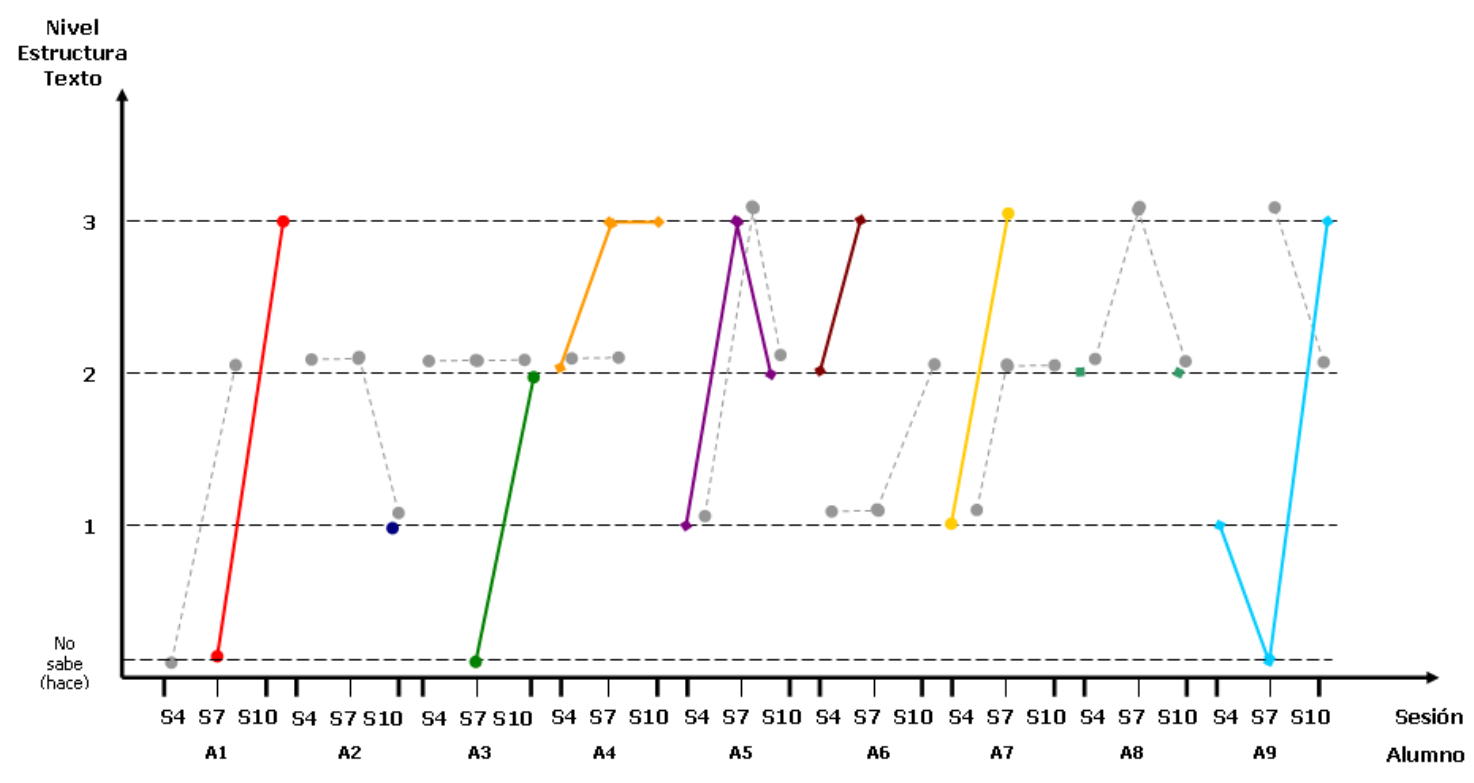

Gráfico 3: Evolución Estructura de Texto y Autopreguntas

Nota: Linea continúa color indica actividad en e-PELS, linea discontinua indica desarrollos en papel (tareas)

Resulta interesante observar que la frecuencia con que los alumnos alcanzan niveles superiores en el uso de la técnica, esto es producción de respuestas significativas, ocurre cuando están frente al computador. En papel, en cambio tienden a mantenerse en el nivel de integración donde asimilan cada elemento de la estructura como un "contenedor de contenido”. Es probable que el efecto motivador de la aplicación computacional, sumado a la interacción con sus pares, provoque tal diferencial. Se observa además facilidad en la adquisición de la técnica y su dominio sostenido.

A continuación se presentan un ejemplo que evidencia el uso de estas estrategias lectoras. Las facilidades otorgadas en e-PELS en cuanto al diseño de una estructura asistida por íconos e imágenes sugerentes parecieran dar resultado en los aprendices. 
La figura 7 es un ejemplo claro de reconocimiento de la estructura que subyace al texto fuente, en el que se observa coherencia en la incorporación y articulación de respuestas.

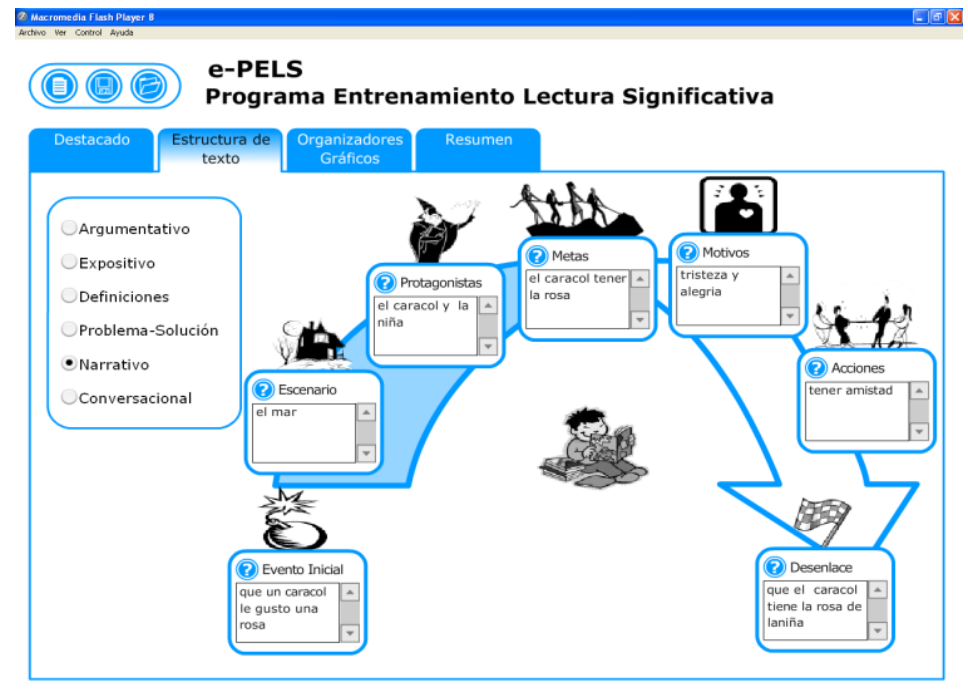

Figura 7: Integración y Coherencia en Estructura de Texto

Hasta hora, la evidencia demuestra que los alumnos han sido capaces de atender incrementalmente a los elementos explícitos del texto, evidenciando, al menos, una comprensión superficial de los desafíos lectores que han debido sortear durante el entrenamiento. En otras palabras, hasta aquí, los alumnos han sido capaces de explorar, procesar y reproducir la lectura, manteniendo el sentido original del texto fuente. Observamos principalmente capacidad de retención de contenido y procesamiento elaborativo, propios del dominio de estrategias de adquisición y codificación, como las descritas hasta ahora.

Por otra parte, es incipiente aún el hallazgo de ilaciones que traduzcan a códigos lingüísticos propios del alumno tales lecturas, iniciándose tibiamente la vinculación de los conocimientos previos del alumno con aquellos presentes en los textos fuentes.

\section{Organizador Gráfico}

Para el análisis de la estrategia que se relaciona con los organizadores gráficos se utilizaron los siguientes indicadores que constituyen una rúbrica de evaluación cualitativa basada en una lista de cotejos. 
Tabla 6: Indicadores Evaluación Organizador Gráfico Interactivo

\begin{tabular}{|c|l|}
\hline \hline Indicador & \multicolumn{1}{c|}{ El alumno: } \\
\hline $\begin{array}{c}\mathbf{1} \\
\text { Pertinencia }\end{array}$ & $\begin{array}{l}\text { Selecciona el OGI más adecuado al contenido o estructura explícitos en el } \\
\text { texto fuente. }\end{array}$ \\
\hline $\mathbf{2}$ & $\begin{array}{l}\text { Incorpora los conceptos claves y explícitos del texto, considerando la estruc- } \\
\text { tura y relaciones pre-establecidas en los OGI's. }\end{array}$ \\
\hline $\begin{array}{c}\text { Integración } \\
\mathbf{3}\end{array}$ & $\begin{array}{l}\text { Demuestra coherencia en la utilización de los OGI's para aclarar y exponer } \\
\text { ideas más allá de lo que explicita el texto fuente. }\end{array}$ \\
\hline $\begin{array}{c}\text { Significación } \\
\text { Hace operativa una red de conceptos y relaciones al utilizar los OGI's para } \\
\text { ejemplificar o relacionar ideas de la fuente con su propia experiencia. }\end{array}$ \\
\hline
\end{tabular}

La siguiente tabla sintetiza los resultados alcanzados por los estudiantes con respecto al uso de los Organizadores Gráficos como estrategia de aprendizaje. Si bien se presentan los 9 que contempla e-PELS en su versión original, se puede observar que no todos fueron utilizados durante las sesiones en que se proponían como un alternativa para el procesamiento y la elaboración y organización de ideas propias. Se tomaron como referencia las sesiones 6,9 y 11 (si la sesión no aparece, indica que no se registra actividad en relación a los organizadores gráficos). El organizador Línea del Tiempo también se incluía en e-PELS, pero ningún alumno lo utilizó.

Tabla 7: Evaluación Organizadores Gráficos

\begin{tabular}{|c|c|c|c|c|c|c|c|c|c|c|c|c|c|c|c|c|c|c|c|c|c|c|c|}
\hline \multirow{3}{*}{$\begin{array}{l}\text { Organizador } \\
\text { Gráfico en } \\
\text { e-PELS }\end{array}$} & \multicolumn{23}{|c|}{ Alumno/Sesión } \\
\hline & \multicolumn{2}{|c|}{ A1 } & \multicolumn{2}{|c|}{$\mathbf{A 2}$} & \multicolumn{3}{|c|}{$\mathbf{A 3}$} & \multicolumn{3}{|c|}{ A4 } & \multicolumn{3}{|c|}{ A5 } & \multicolumn{3}{|c|}{ A6 } & \multicolumn{2}{|c|}{ A7 } & \multicolumn{3}{|c|}{ A8 } & \multicolumn{2}{|c|}{ A9 } \\
\hline & 9 & 11 & 9 & 11 & 6 & 9 & 11 & 6 & 9 & 11 & 6 & 9 & 11 & 6 & 9 & 11 & 9 & 11 & 6 & 9 & 11 & 9 & 11 \\
\hline \multirow[t]{2}{*}{ Pro y Contra } & & & & & 3 & & & & & & & & & & & & & & & & & & \\
\hline & & & & 1 & 3 & & 3 & 3 & 3 & & & & & 2 & & 1 & & 3 & & & 2 & & 1 \\
\hline \multirow[t]{2}{*}{ Causa Efecto } & & & & & & & & 2 & & 2 & & & & & & & & & & & & & \\
\hline & 1 & & & & & & & & & & & & & & & & & 3 & & 1 & 1 & & 3 \\
\hline \multirow{2}{*}{$\begin{array}{l}\text { Diferencias y } \\
\text { Similitudes }\end{array}$} & & & & & & & & & & 3 & & & & & & & & & & & 2 & & \\
\hline & & & & & & & & & & & & & & & & & & & & & & & \\
\hline \multirow{2}{*}{$\begin{array}{l}\text { Espinas de } \\
\text { Pescado }\end{array}$} & & & & & & & & & & & & & & & & & & & 1 & & & & \\
\hline & & & & & & & & & & & & & & & & & & & & & & & \\
\hline \multirow[t]{2}{*}{ Analogía } & 1 & 2 & & & 3 & 1 & 1 & 3 & 2 & & 3 & 1 & 1 & & & 2 & & & & & 2 & 3 & \\
\hline & 1 & & & 1 & 3 & 1 & 1 & 1 & & & & & 1 & & & 1 & 1 & 1 & 3 & & 1 & 1 & 1 \\
\hline \multirow[t]{2}{*}{ Definición } & & & & & & & 3 & & 3 & 3 & & & & & & & & & & & & 1 & 1 \\
\hline & & & & & & & & & & & & & & & & & & & & & & & \\
\hline \multirow{2}{*}{$\begin{array}{l}\text { Comparación } \\
\text { Simple }\end{array}$} & & & & & & & & & & & & & & & & & & & & & & & \\
\hline & & & & 1 & & & 1 & & & & & & & & & & & & & & 1 & & \\
\hline \multirow{2}{*}{$\begin{array}{l}\text { Diagrama de } \\
\text { Secuencias }\end{array}$} & 1 & 2 & 1 & 2 & & 1 & 1 & & 1 & 1 & & 1 & & 1 & & & & & 1 & & 2 & 1 & \\
\hline & & & & & 1 & 1 & & & & & 1 & 1 & & & 2 & & 1 & & & & & & \\
\hline
\end{tabular}

Nota: Ver correspondencia números en tabla 6. Azules: uso de OGI's en e-PELS; Rojos: uso de OGI's en papel (tareas). 
Es importante hacer notar que si bien los organizadores gráficos interactivos no constituyen un problema desde el punto de su manejo y navegación, contemplan destrezas y habilidades de orden superior, que se consiguen luego de haber alcanzado la suficiente madurez intelectual y procedimental. Operaciones como la observación, la comparación, la clasificación, la inferencia, el análisis y la síntesis, se encuentran en un nivel de desarrollo inicial, como se demuestra en esta investigación. El potencial del organizador gráfico como herramienta pro aprendizaje queda limitado, ya que se requiere no sólo de un proceso de instrucción más profundo sino que también de un proceso individual de descubrimiento, aplicación y reflexión (Marzano, Pickering y Pollock., 2001).

Resulta, entonces, aventurado pronosticar que los aprendices sometidos a experimentación evalúen en continuo sus prácticas y estrategias para alcanzar mejores resultados dado el acotado período de entrenamiento.

Al respecto, su reconocimiento como herramienta para elaborar su pensamiento y el reconocimiento de la funcionalidad básica de cada uno de ellos es a todas luces un éxito. Si luego de esta práctica inicial lograsen recurrencia, es decir, su evocación y utilización estratégica, sin lugar a dudas mejoraría no sólo su comprensión lectora sino su capacidad de razonar adecuadamente. Este desafío debe orientarse según se deduce de esta primera experiencia hacia una actividad formativa colaborativa en donde el dominio o, mejor dicho, la automatización de la estrategia se construyan simultáneamente en presencia de otros y con otros.

Así, entonces, es posible encontrar a los organizadores gráficos interactivos siendo percibidos a lo más como herramientas para un procesamiento de primer nivel o elaborativo, escapando por ahora de la posibilidad de ser concebidos como estrategias de procesamiento profundo. Si los estudiantes no son aún capaces de darse cuenta de cómo construyen su propio conocimiento, de rescatar de sus éxitos de aprendizaje aquellas técnicas y estrategias que le han resultado efectivas, en fin, de discriminar en torno a los medios a utilizar para alcanzar conocimientos, sólo insistirán en cumplir con los resultados esperados externamente en torno a retener, reproducir y memorizar sólo lo más inmediato. En definitiva el OGI entendido como "contenedor" es por ahora una primera aproximación a su uso instrumental en entrenamientos posteriores. 
Por último, la búsqueda de niveles superiores de procesamiento que involucren mayor capacidad de síntesis y abstracción, y en donde los organizadores gráficos interactivos no sólo refuercen la comprensión acerca de un determinado contenido sino también resulten útiles en la integración de nuevos conocimientos y en la detección oportuna y autónoma de conceptos erróneos, es un capítulo pendiente para este programa de entrenamiento.

El siguiente organizador gráfico (figura 8) demuestra que los alumnos son capaces de incorporar y ordenar ideas propias a propósito del texto, ya desde las primeras sesiones. Este organizador fue compuesto durante la sesión 6 y en donde se exhibe un primer nivel de composición y vinculación a su experiencia previa.

Sin embargo, observamos con cierta regularidad casos de alumnos que no fueron capaces de demostrar un uso apropiado de los organizadores gráficos, en tanto, su propósito para el desarrollo de habilidades de pensamiento que representan. Muestra de ello se advierte en la figura 9, en donde el alumno no advierte la lógica de la secuenciación propia de este organizador gráfico, convirtiéndolo en un simple contenedor de su particular relato del texto fuente (desarrollado en sesión 9).

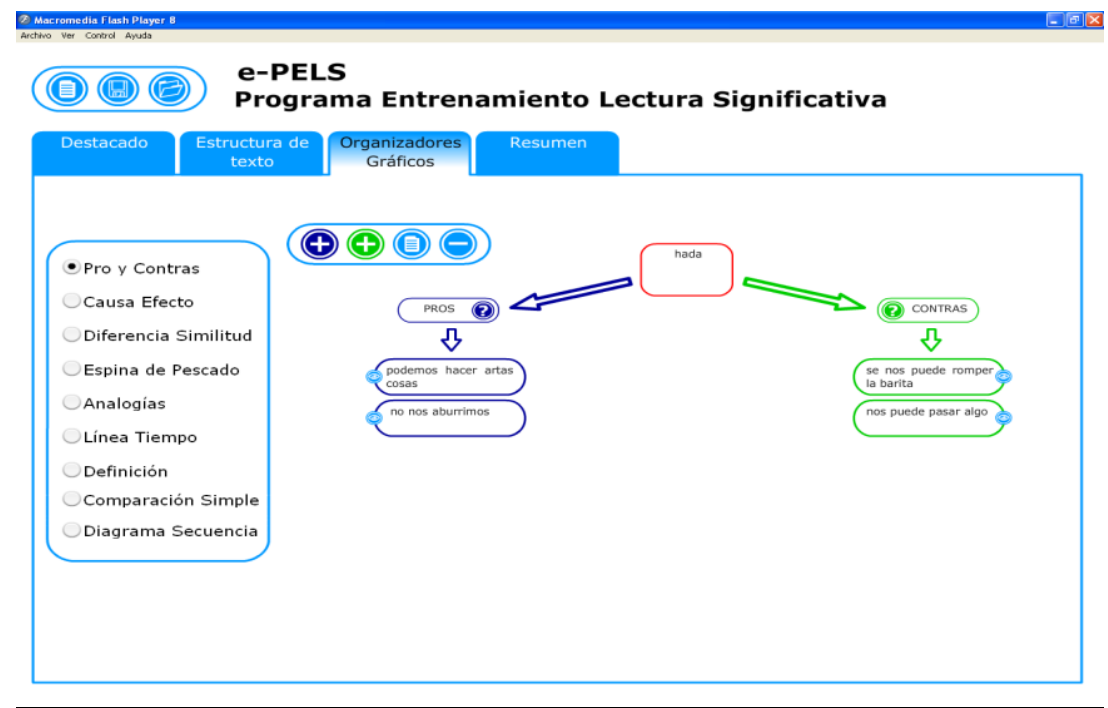

Figura 8: Producción de OGI Pertinente 


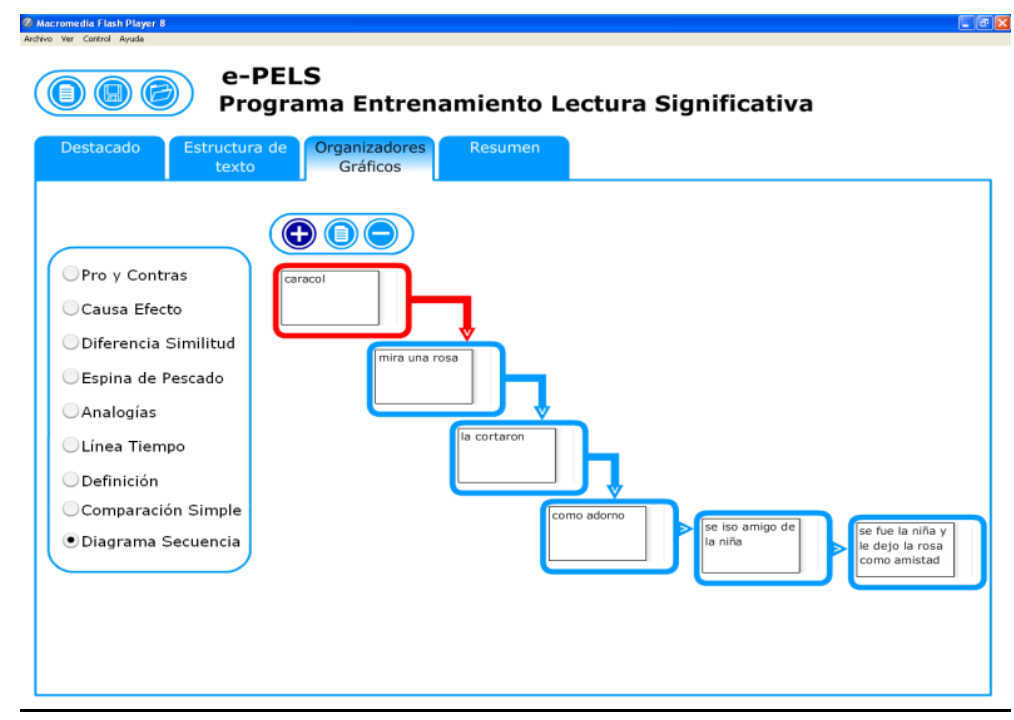

Figura 9: Producción OGI no Pertinente

El siguiente organizador gráfico (figura 10) demuestra que el alumno, eligiendo libremente el organizador que se adecua al texto y a sus ideas, es capaz de generar razonamientos básicos que dan cuenta de un mayor nivel de desarrollo de la destreza.

En organizador gráfico siguiente (figura 11) se observan la integración de las propias experiencias del aprendiz (conocimientos previos), es decir, aquellas que le dan sentido a su propio aprendizaje. En este ejemplo existe una correcta articulación y composición, respetuosa de la fuente y las experiencias personales, todas ellas indicadoras de que la habilidad para conceptualizar ha sido alcanzada.

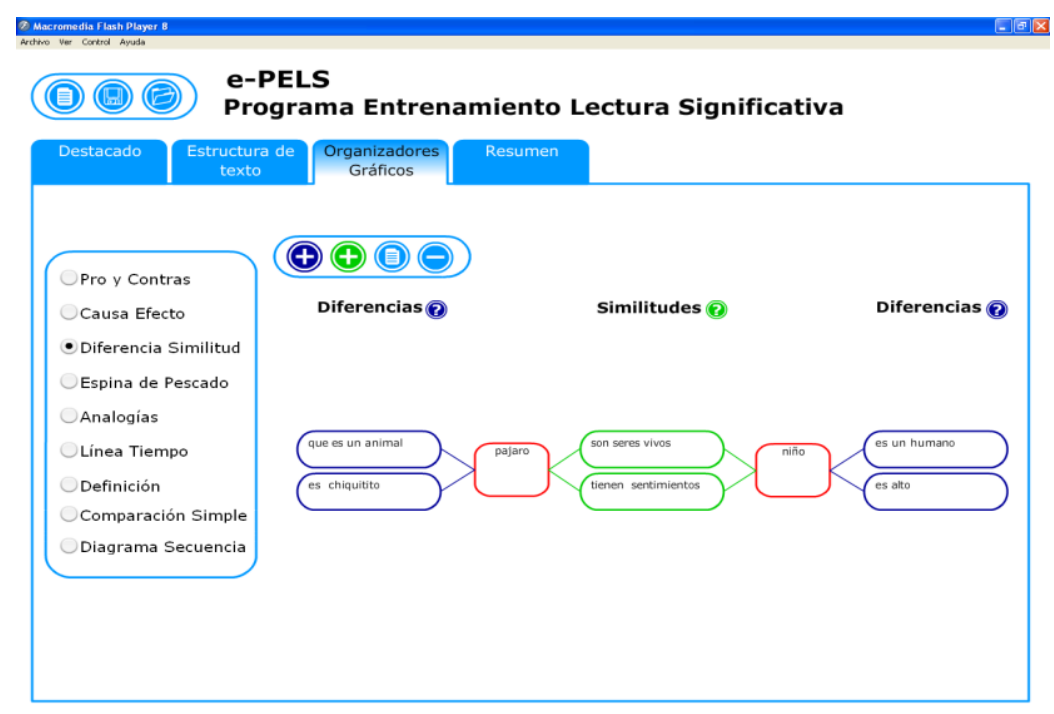

Figura 10: Alineamiento OGI y Destreza 
Sin duda, dados los resultados del entrenamiento en organizadores gráficos interactivos, que aún se encuentran lejos del óptimo, salvo excepciones, comienzan a evidenciar su potencial cómo estrategias que permiten vincular los aspectos de adquisición y codificación de información con aquellas ligadas a la recuperación constructiva de conocimiento.

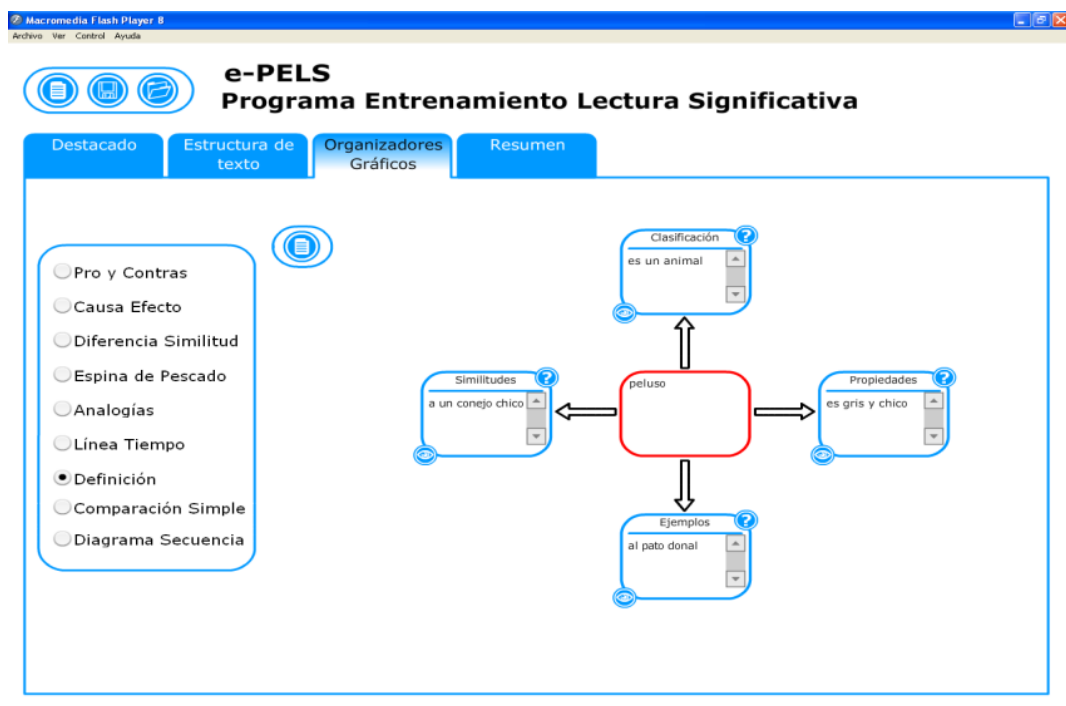

Figura 11: Producción Significativa de OGI

\section{Conclusiones}

En la medida que los alumnos del grupo experimental avanzaron en el entrenamiento de cada una de las estrategias de aprendizaje lector provistas en e-PELS se observó, primero, el reconocimiento progresivo de la técnica, y segundo, luego de la iteración y uso sistemático, su potencial instrumental para lograr mejores niveles de comprensión. En este último sentido, la situación experimental evidenció que el alumno decide y logra un uso conciente y recurrente de la técnica en la medida que se enfrenta a nuevos desafíos lectores, convirtiéndola en estrategia de aprendizaje durante el desarrollo del programa de entrenamiento.

Resultados similares se observan en el trabajo experimental de Román (2004), y que inspiraron este trabajo, quien concluye que los alumnos que participaron de su programa de entrenamiento en estrategias de aprendizajes, análogas a las de e-PELS pero sin apoyo de software, incrementaron significativamente el dominio de dichas estrategias. Sin embargo, en dicho trabajo, el mejoramiento de la comprensión lectora queda circunscrito a un plano potencial e indirecto. 
Otras evaluaciones experimentales también señalan las ganancias observadas al entrenar en estrategias de aprendizaje, ya sea enseñando técnicas específicas, como los mapas conceptuales (Güvenç y Ün Açikgöz, 2007) u organizadores gráficos (Strangman, Hall y Meyer, 2003) como en el desarrollo y uso de aplicaciones de software específicas para este propósito (Millis, Kim, Todaro, Magliano, Wiemer-Hastings y McNamara, 2004; Tsai, Lin y Yuan, 2001).

El programa e-PELS ha demostrado constituirse en un elemento que operacionaliza la significación de los aprendizajes; asiste en la vinculación entre los conocimientos o experiencias previas de los estudiantes y los nuevos contenidos que enfrentan. Es decir, no sólo durante el desarrollo de esta experiencia se evidenció el dominio y evolución de cada una de las estrategias de aprendizaje, sino que principalmente la instanciación de aprendizajes más significativos por parte del alumno durante el entrenamiento.

Los resultados demuestran que se comienza a abandonar la reproducción literal y la consiguiente memorización se va sutituyendo por la incorporación de elementos propios presentes en la estructura cognitiva previa de los alumnos, donde la antigua reproducción con fines de retención del contenido, evoca ahora elementos explícitos, pero con un tratamiento personal principalmente dado por el lenguaje habitual que utilizan y la cita de experiencias personales que forman analogías que acrecientan la aprehensión y luego el aprendizaje profundo.

Además, nos encontramos con alumnos, que pese a presentar aún deficiencias en sus niveles de comprensión lectora, medido en términos tradicionales, cuentan hoy con una dotación de estrategias de aprendizaje que les permitiría enfrentar desafíos lectores y de aprendizaje con independencia de las áreas del conocimiento (transversalidad). Así, entonces, la lectura y comprensión significativa de un texto va dejando evidencias de un proceso estratégico incremental, fundiéndose tales procesos con la producción cada vez más significativa de pequeños trozos de texto.

Un aporte notoriamente visible donde se requiere de una mirada estratégica es la propiedad de e-PELS de hacer visible el particular proceso de construcción del conocimiento de cada aprendiz lector. Transparentar procesos cognitivos y el ejercicio del estado de sus habilidades lectoras permite no sólo visualizar su nivel de comprensión sino que además posibilita 
al docente una evaluación verdaderamente centrada en el proceso de aprendizaje. Con ello se consigue una oportunidad de intervenir tal proceso - comprensión lectora - atendiendo directamente a la habilidad que pudiese encontrase en un estado deficitario para tal finalidad o potenciando aquellas que resultan de utilidad.

Queda, sin embargo, por demostrar la transferencia y durabilidad de las habilidades desarrolladas para el procesamiento de información a contextos distintos al experimental. Otras experiencias indican que la presencia de actividades en que los docentes estimulan el uso de las estrategias de aprendizaje enseñadas resulta fundamental para lograr su transferencia y durabilidad (Román, 2004; Strangman et al., 2003).

Finalmente, la aplicación e-PELS demuestra ser una herramienta poderosa para el aprendizaje lector que permite poner énfasis en las competencias, habilidades y destrezas, como fines últimos del aprendizaje. En sintonía con las corrientes pedagógicas vigentes, ePELS se configura como un mecanismo de procesamiento de contenidos al servicio del dominio de las estrategias y de la materialización de la competencia lectora bajo un enfoque de aprendizaje significativo y que en todo momento apunta a la transferencia de la competencia que se va adquiriendo más allá de la experiencia lectora particular con e-PELS en el computador. 


\section{Referencias}

Alliende, F., Condemarín, M. y Milicic, N. (2004). Prueba CLP Formas Paralelas: Manual para la aplicación de la prueba de comprensión lectora de complejidad lingüística progresiva, 8 niveles de lectura. $7^{\text {a }}$ edición. Santiago: Ediciones Universidad Católica de Chile.

Amestoy, M. (2002). La investigación sobre el desarrollo y la enseñanza de las habilidades de pensamiento. Electronic Journal of Research in Educational Psychology/Revista Electrónica de Investigación Educativa, 4 (1), 129-159. (www.investigacionpsicopedagogica.org/revista)

Ausubel, D. (1963). The Psychology of Meaningful Verbal Learning. Nueva York: Grune and Stratton.

Bara, P. (2001). Estrategias Metacognitivas y de Aprendizaje: Estudio empírico sobre el efecto de la aplicación de un programa metacognitivo, y el dominio de las estrategias de aprendizaje en estudiantes de E.S.O, B.U.P y Universidad. Madrid: Universidad Complutense. Facultad de Educación. Dpto. de Didáctica y Organización Escolar.

Condemarín, M. y Medina, A. (2000). Evaluación Auténtica de los Aprendizajes: Un medio para mejorar competencias en lenguaje y comunicación. Santiago: Editorial Andrés Bello.

Güvenç, H. y Ün Açikgöz, K. (2007). The Effects of Cooperative Learning and Concept Mapping on Learning Strategy Use. Educational Sciences: Theory \& Practice, 7 (1), 117-127.

Kolb, D. (1984). Experiencial Learning: experience as the source of learning and development. New Jersey: Prentice-Hall.

Marzano, R., Pickering, D. y Pollock, J. (2001). Classroom Instruction that Works: Research Based Strategies for Increasing Student Achievement. Virginia: Association for Supervision and Curriculum Development.

Millis, K, Kim, H., Todaro, S., Magliano, J., Wiemer-Hastings, K. y McNamara, D. (2004). Identifying reading strategies using latent semantic analysis: Comparing semantic benchmarks. Behavior Research Methods, Instruments, \& Computers, 36 (2), 213-221.

MINEDUC (2003). Desempeño de los estudiantes chilenos: resultados de PISA. Santiago de Chile: Departamento de Planificación y Presupuesto del Ministerio de Educación de Chile. 
MINEDUC (2006). Recursos Curriculares de Base. Ministerio de Educación de Chile. Santiago de Chile. (http://www.mineduc.cl) Acesado 05/08/2006.

Monereo, C. (1991). Enseñar a pensar a través del currículm escolar. Barcelona: Casals/COMAP.

Novak, J. y Gowin, B. (1988). Aprendiendo a Aprender. Barcelona: Martínez Roca.

OECD (2000). Literacy in the Information Age. Paris: Organization for Economic Cooperation and Development - Statistic Canada.

Pezoa, C. y Labra, J. (2002). Estrategias de Aprendizaje una Propuesta en el Contexto Universitario. Santiago de Chile: Ediciones Universidad Católica Cardenal Raúl Silva Henríquez.

Román, J. M. y Gallego, S. (1994). ACRA: Escalas de estrategias de aprendizaje. Madrid: TEA Ediciones.

Román, J. M. (2004). Procedimiento de aprendizaje autorregulado para universitarios: la estrategia de lectura significativa de textos. Electronic Journal of Reasearch in Educational Psychology 2 (1), 113-132. (www.investigacion-psicopedagogica.org/revista)

Román, M. (2005). Sociedad del conocimiento y Refundación de la Escuela desde el Aula. Barcelona: Ventrosa Impresores.

Sepúlveda, G. y Jofré, A. (1984). Escalas Diagnósticas de Lectura de G. Spache. Santiago de Chile: Universidad de Chile. Monografía.

Strangman, N., Hall, T. y Meyer, A. (2003). Graphic Organizers and Implications for Universal Design for Learning: Curriculum Enhancement Report. National Center on Accessing the General Curriculum.

Trufello, I. (1988). Adaptación en Chile del "Inventory of Learning processes" de Ronald Schmeck. Tesis para optar al grado de Magíster en Educación. Facultad de Filosofía, Humanidades y Educación. Santiago de Chile: Universidad de Chile.

Tsai, C., Lin, S. y Yuan, S. (2001). Students' use of web-based concept map testing and strategies for learning. Journal of Computer Assisted Learning, 17 (1), 72-84. 